Anatolij M. Gajdìn*, Jadwiga Maciaszek**, Jacek Szewczyk ${ }^{* * *}$

\title{
The Influence of the Inundation of the Potassium Open Pit in Kalush on the Environment - Predictions and Facts
}

\section{Introduction}

In the Ukrainian city of Kalush (Ivano-Frankiv region) since 1967 until 2005 there was an open pit "Dąbrowski". It exploited potassium. Until 2008 the drainage system functioned. It consisted of the ditch to channel the water outflow from the Quaternary layers and collected brine in the exploited southern part of the mine. In January 2008 the drainage stopped due to bankruptcy of the enterprise. The pit was getting flooded. In July 2008, during a heavy rain, the inundation rapidly accelerated and became irreversible. In the place of the pit a lake was formed, which has already accumulated over $20 \mathrm{mln} \mathrm{m}^{3}$ of brine.

Over the inundation of the pit there is a fierce discussion on its environmental impact. The authors of article [1] stated that the deformations of scarps would be so great that the hole would reach the canal located in the distance of above $200 \mathrm{~m}$ from the northern scarp of the mine. Another probable threat is the salinization of rivers and the Quaternary water-bearing horizon, used as the source of water to be supplied to the residents. The opposite opinion is represented by A.M. Gaydin, which in article [2], based on physical modelling and theoretical calculations, proved that the damage to scarps would not exceed 30-40 m, and the upper part of the water horizon in the future lake would not be saline, thus there would be no threat to the environment. It has been almost five years since the beginning of the inundation of the mine and these predictions were confirmed by direct observations.

\section{Natural Conditions}

The mine is crossing the river valley of Sivka, the waters of which are led through the canal, passing in the distance of $200 \mathrm{~m}$ from the northern scarp of the

\footnotetext{
* National Academy of Sciences of Ukraine, Kiev, Ukraine

** AGH University of Science and Technology, Faculty of Mining Surveying and Environmental Engineering, Krakow, Poland

*** Kielce University of Technology, Kielce, Poland
} 
open pit. The altitude of the surface of the area is about 300-303 m, and the level of water in the canal $-298 \mathrm{~m}$. The geological profile of the deposit of the potassium salt includes three basic substances: potash and salt-bearing breccias of weathered clays and Quaternary formations. The salts include the ones that are easily soluble such as: halite, kainite and sylvite as well as worse soluble: langbeinite, kieserite, polyhalite and anhydrite; additionally there are $15-17 \%$ of insoluble clay fraction. The rocks containing deposit - salt-bearing breccia - consist of clays and sandstones, cemented with halite. They contain up to $45 \%$ of the salt. The withering coating of the salt-bearing rocks - the clay-gypsum cap - is 3-4 m, up to $24 \mathrm{~m}$ thick. The floor of the deposit series is situated on the height of 262-274 $\mathrm{m}$ above the sea level, roof on the height 276-278 $\mathrm{m}$ above the sea level. The Quaternary sediments include 2-18 m thick water-bearing gravel layers, covered by loams of thickness $2.5-6 \mathrm{~m}$. In the southern part of the pit, the slopes are built of salt-bearing breccias and in the northern part of potash.

The volume of exploited deposit in the mine is $52.5 \mathrm{mln} \mathrm{m}^{3}$. The ordinate of the bottom in the southern part of the mine is $173 \mathrm{~m}$ above the sea level, in the northern part - $237 \mathrm{~m}$ above the sea level. The angle of inclination of the slope in loams and gravels is $35^{\circ}$, in the clay-gypsum $-50^{\circ}$. The deposit was made accessible by the removal of the overburden, applying $15 \mathrm{~m}$ high scarps of mean slope $65^{\circ}$. To drain ground waters, around the pit, a $5.3 \mathrm{~km}$ long and $25 \mathrm{~m}$ deep ditch, of the volume of $2.3 \mathrm{mln} \mathrm{m}^{3}$ was dug. The fresh water was pumped from the ditch and released to the river. Between the pit and the draining ditch there was a $100 \mathrm{~m}$ wide pillar. On the northern slope, on the length of $160 \mathrm{~m}$, the pillar was exploited and the trench liquidated. The brine solution, arising from sediments getting onto the surface of the mine, was thrown into the pit, according to the liquidation plan.

\section{The Method of the Studies}

In order to predict the deformations of the pit slopes and the chemical composition of the water in the future lake, the studies were carried out with physical models, observations of the dynamics of flooding the pit, photogrammetric documentation of the state of the slopes, depth measurements and hydro-chemical sampling of the water horizon in the defined intervals.

\section{Deformations of the Pit Slopes}

The main process causing deformations is the dissolution of salts. The solubility of potassium salt is $400 \mathrm{~g} / \mathrm{L}$, and the one of halite is $310 \mathrm{~g} / \mathrm{L}$. Both the deposit and the rocks contain large amount of insoluble ingredients; this is very important for the deformation of slopes. To study this process, a transparent model of a vertical slope of the pit in scale 1:100 was constructed. The salt-bearing layer was 
modelled with the mixture of clay and halite in equal proportions. Over this the imitation of clay-gypsum cap was made of clay. The imitation of the Quaternary layer was made of sand and loam. The pit model formed in such a way was filled with fresh water. The speed of raising the level of water was clearly smaller than the linear speed of the dissolution of halite - according to the observations in natural conditions.

The photo (Fig. 1) shows the formation of the niche in the vertical slope, resulting from the dissolution of salt. The roof of the niche is horizontal and overlaps with the level of the water.

a)

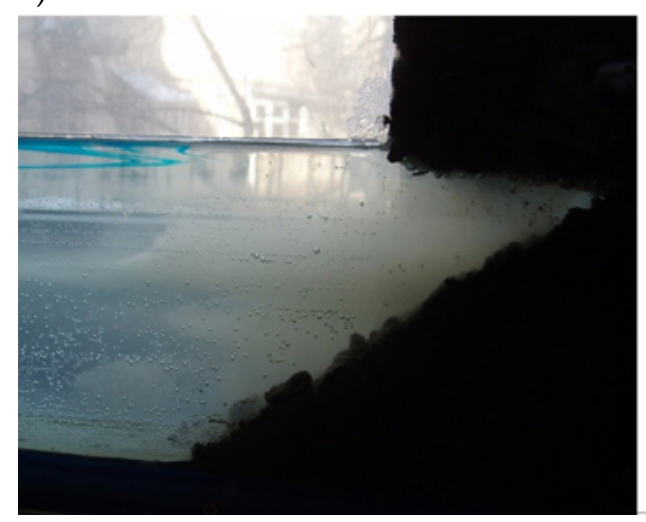

b)

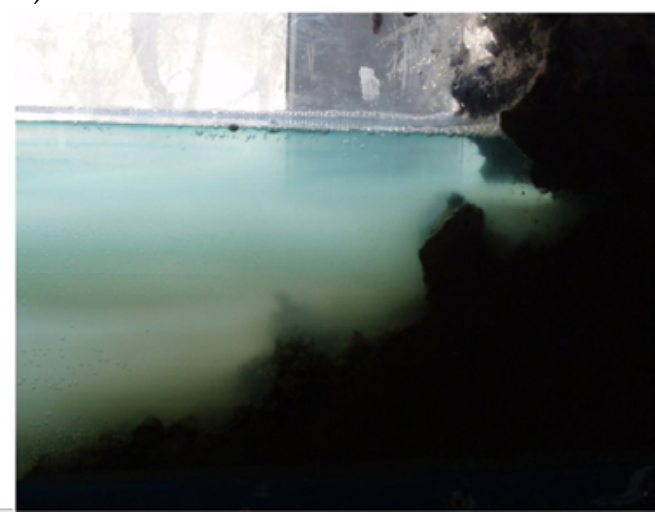

Fig. 1. The model of the pit slope, being dissolved by the fresh water:

a) arising of the niche; b) slope collapse

Insoluble ingredients at the beginning get downwards and are deposited on the bottom. When the angle of the inclination of the side surface to the natural slope gets smaller, the surface of the niche gets isolated from the water horizon and stops dissolving; only the roof gets dissolved. The non-dissolved residue falls from the roof, making the prism inclined according to the angle of the natural slope.

With the growth of level, the depth of the niche increases, and the attached layers of the rocks collapse. The collapsed rock blocks are shattered, get down and accumulated on the bottom (Fig. 2).

Clays, gravels and loams fill the roughness of the bottom. Thin fractions are washed out from the collapsed rocks and gradually settle on the bottom of the lake. Due to their own weight these sediments get sealed and isolate salt from the water horizon.

The formula (1) gives the possibility of calculating the depth of the niche, depending on the content of insoluble ingredients and the depth of the inundation (Fig. 3). 


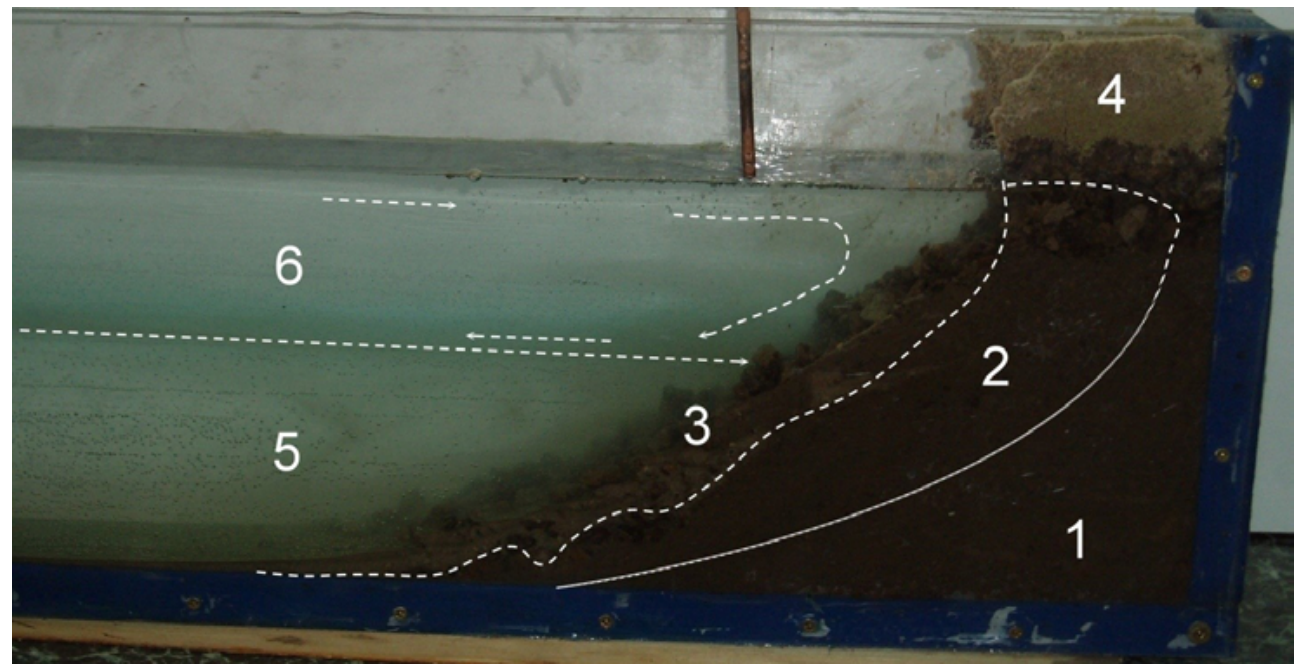

Fig. 2. The pit slope after the collapse (model):

1 - salt, 2 - insoluble sediments, 3 - products of shattering the overburden, 4 - Quaternary formations, 5 - saturated solution, 6 - unsaturated solution. The arrows show the directions of the propagation of the solution (brine)

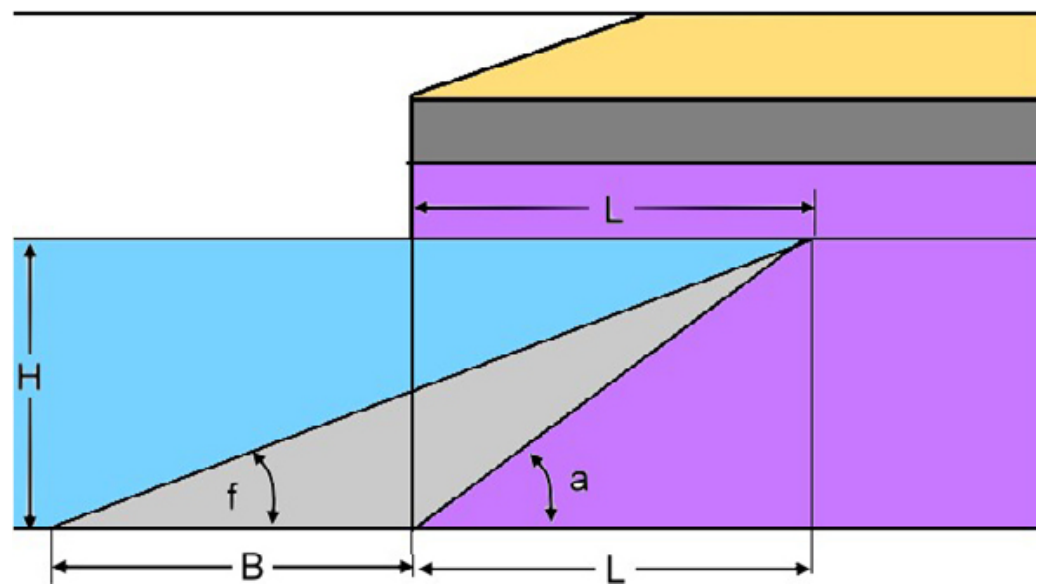

Fig. 3. The calculation scheme to define the parameters of the niche

Area of the triangle occupied by an insoluble precipitate, equals the area of the triangle corresponding to the volume of rock salt dissolved, multiplied by the volume content of insoluble residue, i.e.:

$$
0.5 \cdot B \cdot H=0,5 \cdot H \cdot L \cdot C
$$

$$
B=L \cdot C
$$


During the dissolution of the vertical wall, the depth of the niche $L$ equals:

$$
\begin{gathered}
L=H \cdot \operatorname{ctg} f-B \\
L=H \cdot \operatorname{ctg} f-L \cdot c \\
L+L \cdot c=H \cdot \operatorname{ctg} f \\
L(1+c)=H \cdot \operatorname{ctg} f \\
L=\frac{H \cdot \operatorname{ctg} f}{(c+1)}
\end{gathered}
$$

where:

$H$ - water depth (Fig. 3),

$f$ - the angle of natural slope of insoluble sediments,

$c$ - volume concentration of insoluble ingredients in the rock subdued to dissolution,

$B$ - the distance from the edge of the scarp to the end of the washed out area.

The initially inclined under the angle $\beta$ slope surface of the maximal depth of the niche is defined by the formula:

$$
L=\frac{H \cdot(\operatorname{ctg} f-\operatorname{ctg} \beta)}{(c+1)}
$$

The formula shows that in case of the surface inclination equal or smaller than the angle of the inclination of the slope of insoluble deposits:

$$
f=a, \quad L=0
$$

and there is no dissolution.

\section{Forecasting Calculations}

The proposed method allows the assessment of the scale of the deformation in the pit slopes to predict dangers. In the larger part of the mine deformations appear within the borders of the pillar between the pit and the draining ditch. They do not pose threat to any buildings or instruments. The only dangerous deformations are the ones of the northern slope, in the vicinity of which there is a group of holiday houses.

The northern slope of the pit is built of potash, in which there is $12 \%$ of insoluble material, as well as up to $6 \%$ of poorly soluble polyhalite and $7 \%$ of insoluble kieserite; $25 \%$ in total. The angle of the natural slope of insoluble sediments is - according to the results of the in situ measurements $-11^{\circ}$. Before the inundation, the slope made a $28 \mathrm{~m}$ high scarp, inclined under the angle of $65^{\circ}$. In the case of the inundation to he height of $H=28 \mathrm{~m}$, the depth of the niche will be $100 \mathrm{~m}$ (i.e. the slope the northern 
slope can move towards the initial one of $100 \mathrm{~m}$ ). In fact the slope was flooded to the height of $18 \mathrm{~m}$ and displaced - according to the state of 2012 - by $40-50 \mathrm{~m}$.

The calculated depth of the future vertical dislocation of the slope (10 $\mathrm{m}$ high) in the relation to the present situation is $36 \mathrm{~m}$. The collapse of the slope results in the liquidation of the way going through the slope and will reach the nearest allotments with their influence (Fig. 4). To prevent further collapse making a prism from a local material was proposed. The prism will cover the layers of salt. This proposal was implemented in the west part of the northern slope. This brought the expected result. Further washing out of the shores due to the waves will lead to the end of the salt dissolution.

a)

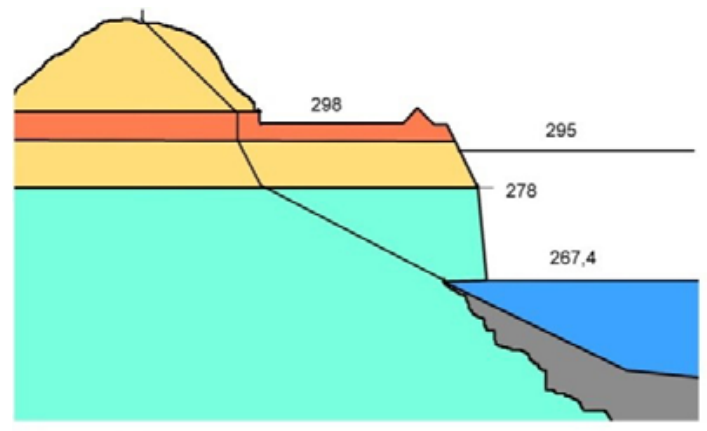

b)

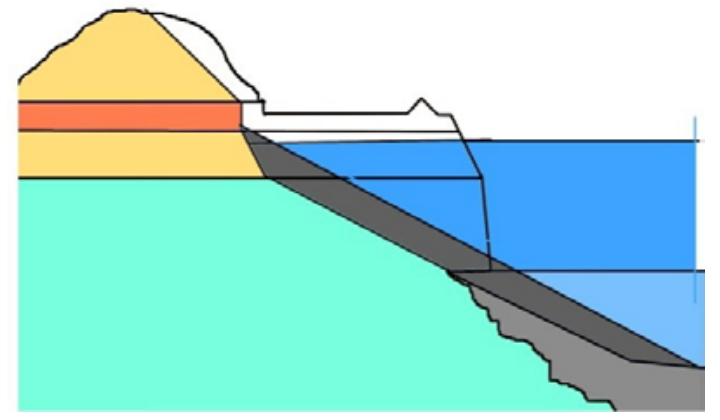

Fig. 4. The prediction of the development of deformation on the northern slope:

a) initial state; b) forecasted state

\section{The Observations}

The observations carried out directly in the pit indicated that the niches were made alongside the whole circuit of the pit (Fig. 5), and their depth ranged from 2 to $5 \mathrm{~m}$. The outer surface of the niches is rough; poorly soluble minerals often make sharp protrusions. After the niche achieves the depth of 3-5 m, the slope collapses, producing rocks at the shore. They are washed by the water and quickly dissolve. After that, the portions of insoluble and poorly soluble minerals remain. 
On the majority of slopes before the inundation shelves were made on the surface of salt-bearing layer and the clay cap. As a result of dissolving the width of the shelves diminished and in the southern part of the pit (flooded much earlier) shelves do not exist. The solution of the salt is accompanied by the landslides of clay and Quaternary gravels, which cover the shore. As shown in Figure 5, such sections of the shore are covered with trees.
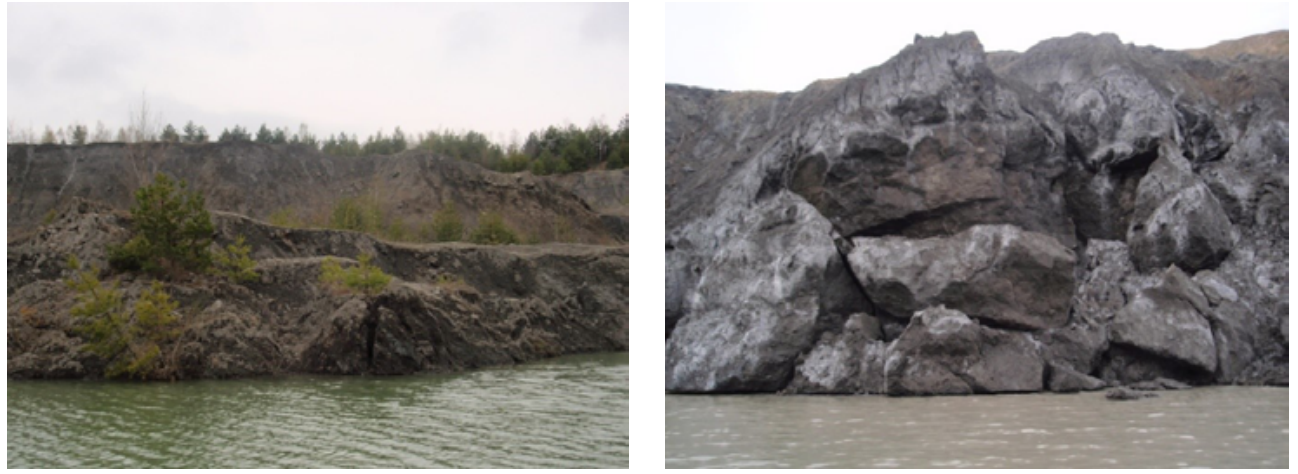

Fig. 5. Landslide and caving of the lake "Dąbrowski" shore, 2011

As it was shown in the measurements of the submerged border scarps, the slope pit initially inclined under the angle up to $50^{\circ}$, decreased the inclination up to $29^{\circ}$, and near the bottom - up to $17^{\circ}$. Scarps and shelves do not exist. In the northern part the inclination of the bottom is only $11^{\circ}$ (Fig. 6).

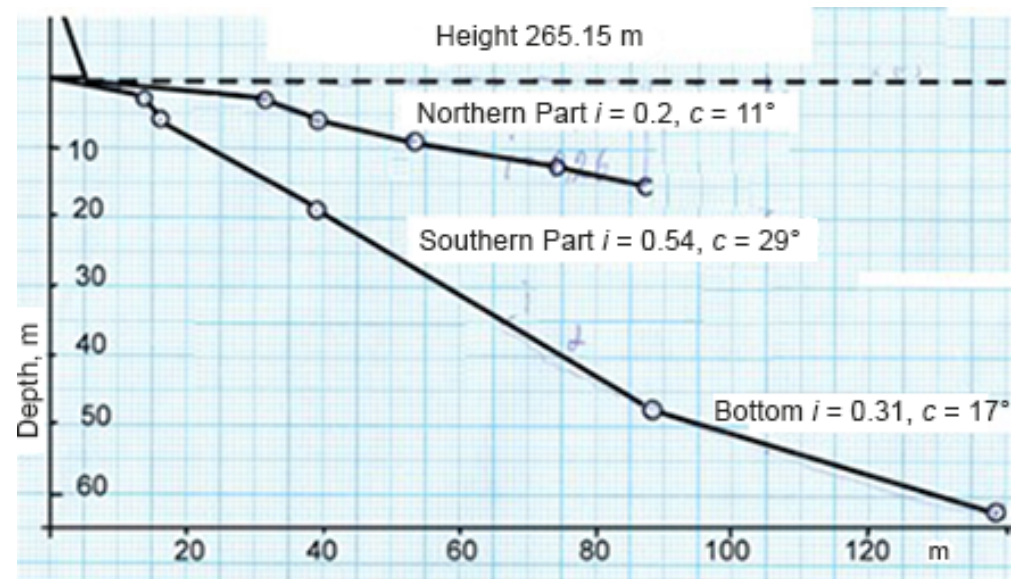

Fig. 6. The profiles of the bottom of the lake (the height above the sea level: $265.15 \mathrm{~m}$, northern part, southern part, bottom - inclination). Slope of the pit slopes (in units: $c$-degrees, $i$-dimensionless)

Source: [2] 
Washing out the shores due to wind waving in the period of flooding salt-bearing rocks is not very important, because high shores protect the water mirror against the wind. Intensive washing out is expected after raising the water level to the level of the deposition of easily soluble Quaternary formations. As indicated by the results of the calculations, the depth of washing out is $40 \mathrm{~m}$; the products of washing out definitely protect the salt protrusions.

Thus during the deformation of the slopes the following stages can be differentiated:

1) the formation of niches - dissolution,

2) collapse,

3) washing out Quaternary layer due to the waves.

\section{Chemical Composition of Water}

The studies of the deformation of pit slopes showed that the accumulation of insoluble residues and the collapse of the overburden, leads to the isolation of salt from the water horizon and stopping the processes of dissolution.

Given below formulae allow the calculation of the amount of salt, which is dissolved during the inundation of the pit. The volume of salt-bearing rocks $V$, dissolved during the inundation is defined by the formula:

$$
V=0.5 \cdot P \cdot H \cdot L
$$

where:

$H$ - slope height,

$L$ - depth of the niche,

$P$ - length of the section of the pit slope with the defined parameters.

The mass of dissolved salt $M$ equals:

$$
M=0.5 \cdot P \cdot H \cdot L \cdot(1-c) \cdot \gamma
$$

where $\gamma$-spatial density of the rocks.

The mean level of the mineralization of the solution (brine) after the inundation of the salt-bearing layer equals the ratio of the dissolved salt to the volume of water, which in the height range $250-278 \mathrm{~m}$ above the sea level is $16 \mathrm{mln} \mathrm{m}^{3}$.

For the sake of preliminary assessment let us assume $H=28 \mathrm{~m}, L=25 \mathrm{~m}$, $P=5000 \mathrm{~m}, c=0.5, \gamma=2100 \mathrm{~kg} / \mathrm{m}^{3}$. After putting the data we obtain $M=1840 \mathrm{mln} \mathrm{kg}$. Mean level of the mineralization of solution is $114 \mathrm{~kg} / \mathrm{m}^{3}$. The real degree of the concentration of solution in the upper part of the water horizon is presented in Table 1. 
Table 1. Changes in the concentration of the solution in the northern part of the pit

\begin{tabular}{||l|c|c|c|c|c||}
\hline \multirow{2}{*}{ Mineralization [g/L] } & \multicolumn{5}{|c||}{ Depth [m] } \\
\cline { 2 - 6 } & 0 & 3 & 5 & 10 & 20 \\
\hline \hline April 2009 & 165 & - & 301 & 327 & - \\
\hline April 2010 & 148 & - & 222 & 222 & 310 \\
\hline June 2010 & 128 & 192 & 222 & 222 & - \\
\hline March 2012 & 108 & - & - & - & 300 \\
\hline March 2014 & 20 & 105 & 180 & - & - \\
\hline
\end{tabular}

As shown in the table, mineralization of the solution diminishes with time, and the real values do not vary much from the calculations.

\section{Accumulation of Fresh Water}

From the moment of the collapse of the edges the dissolution of salt ceases, and the fresh water, coming from Quaternary formations and atmosphere, accumulates over the brine. On the surface of the lake there will be about $1 \mathrm{mln} \mathrm{m}^{3}$ of precipitation. The level of water in lake, after the inundation will stay on the height of $295 \mathrm{~m}$ above the sea level, i.e. $3 \mathrm{~m}$ lower than the level of water on the borders of supply - in the canal and in the river Sivka. Thus the lake will be the place of the influence of waters from the Quaternary water bearing horizon.

Due to the difference in density, fresh water propagates over the surface of the solution (brine), almost not mixing with it (Fig. 7). The thickness of the fresh water layer corresponds the difference between the height of the inundation (296 $\mathrm{m}$ above the sea level) and the height of the roof of salt bearing layer (278 $\mathrm{m}$ above the sea level), i.e. $18 \mathrm{~m}$.

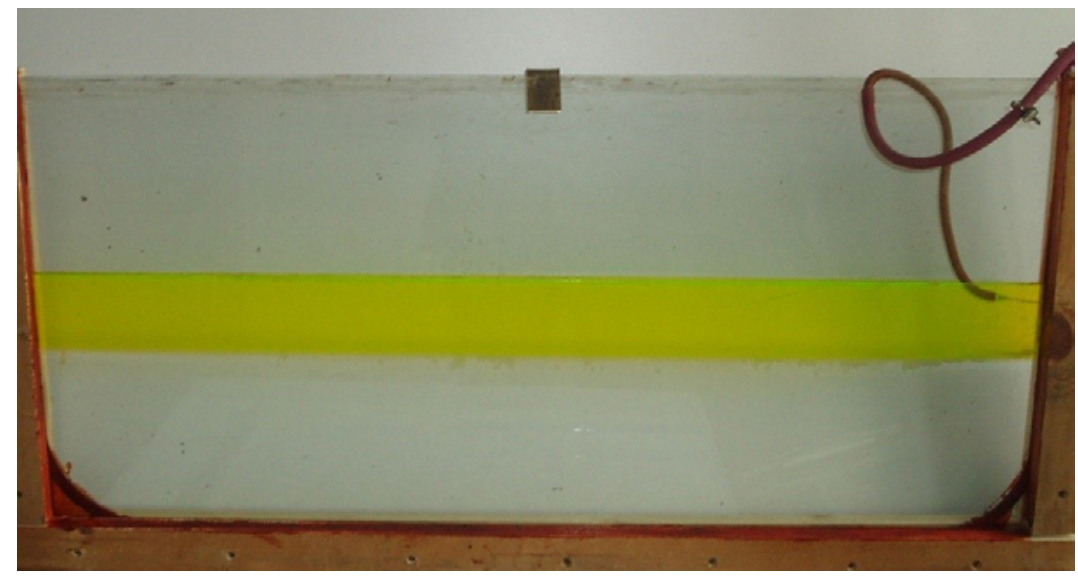

Fig. 7. The propagation of fresh water (light colour) on the surface of the solution in the model 
To show the phenomenon of the gravitation of the division between saline water and fresh water to the lower part of the described above model, the solution of the concentration $320 \mathrm{~g} / \mathrm{L}$ was poured. Then on the surface of the solution coloured fresh water was pumped. As shown on the photograph (Fig. 7), fresh water flows on the surface, not mixing with the solution. Fresh water will be collected on the upper part of the water horizon, while the saturated solution (brine) - lower part.

This way in the place of mine "Dąbrowski" a double layer lake was formed. The lake contains fresh water up to the depth of $18 \mathrm{~m}$ and the solution (brine) below.

\section{Conclusions}

In the mechanism of changing the shores during the inundation of the salt mine, the following stages can be differentiated: 1) dissolution of salt on the slopes and the formation of niches, 2) collapse of insoluble rocks over the niches, 3) washing off the rocks under the influence of wave movements.

As a result of the transformation of the edges, salt bearing layers get isolated from the water horizon, and consequently, the brine is formed only in the period of flooding the salt-bearing rocks.

During the formation of the chemical composition of water in the lake formed in the place of the pit, two stages can be differentiated: 1) the arising of brine during the formation of the salt-bearing layer, 2) accumulation of fresh water during the inundation of the Quaternary formations.

In the place of the pit a lake is formed with the saline water on the bottom and a surface layer of fresh water of the thickness up to $18 \mathrm{~m}$.

This way it was proved that it is possible to form a lake in the place of a potassium open pit. The lake is possible to be used in recreation. It is reasonable to apply the results of the studies as the basis of the project of the revitalization of the area in the zone of the influence of the "Dąbrowski" mine.

\section{References}

[1] Semčuk Â.M., Savčuk L.Â.: Ekologičnì problemi Kalus'kogo gìrničopromislovogo regìnu ta šlâhi îh virišennâ. Ekologična bezpeka ta zbalansovane resursokoristuvannâ, no. 1, 2010, pp. 64-69.

[2] Gajdìn A.M.: Ozero v Dombrovs'komu kalìjnomu kar'êrì. Ekologična bezpeka ta zbalansovane resursokoristuvannâ, no. 2(4), 2011, pp. 55-62. 